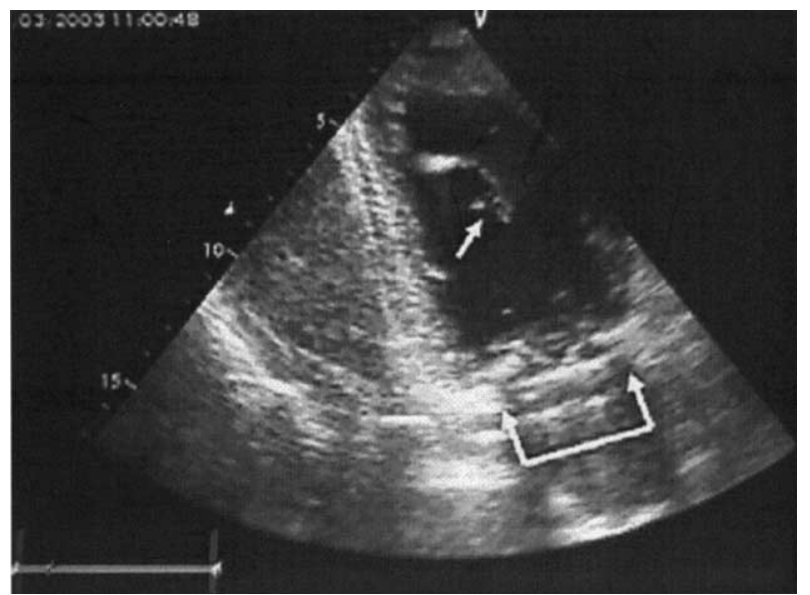

Figure 1. Transthoracic echocardiogram (apical, 2-chamber view) showing mitral prosthesis (double arrow) and structure (attached on posterior papillary muscle) floating in the left ventricular cavity (arrow).

\section{References}

1. Ohkita Y, Miki S, Ueda Y, Tahata T, Ogino H, Sakai T, et al. Mid-term results of mitral valve replacement combined with chordae tendineae replacement in patients with mitral stenosis. J Heart Valve Dis. 1997; 6:37-42.

2. Lemke P, Roth M, Kraus B, Hohe S, Klövekorn W, Bauer E. Ruptured papillary muscle after mitral valve replacement with preservation of chordae tendineae. Ann Thorac Surg. 2001;72:1384-6.

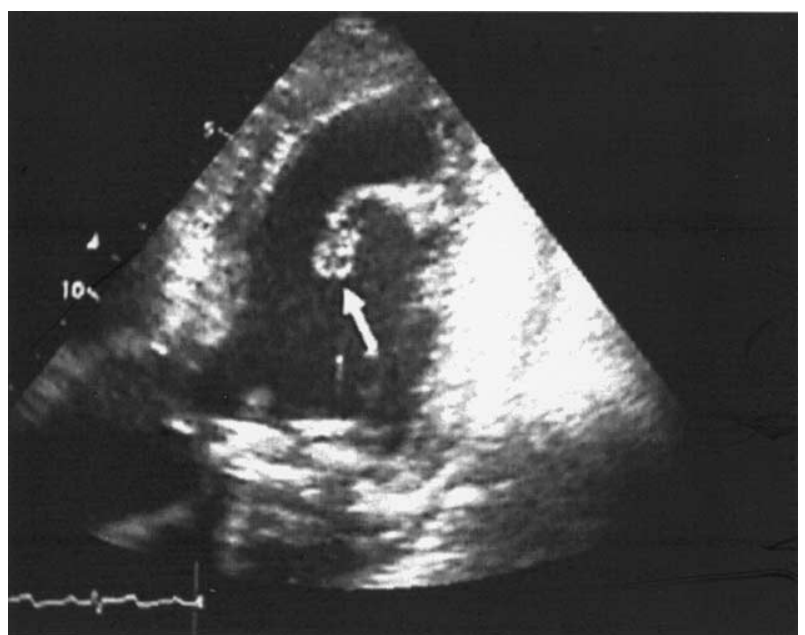

Figure 2. Transthoracic echocardiogram (apical, 4-chamber view) showing the torn remnant of the spared anterior leaflet still attached to the posterior papillary muscle (arrow).

3. Rietman GW, van der Maatan JM, Douglas YL, Boonstra PW. Echocardiographic diagnosis of left ventricular outflow tract obstruction after mitral valve replacement with subvalvular preservation. Eur J Cardiothorac Surg. 2002;22:825-7.

4. Mok CK, Cheung DL, Chiu CS, Aung-Khin M. An unusual lethal complication of preservation of chordae tendineae in mitral valve replacement. J Thorac Cardiovasc Surg. 1988;95(3):534-6.

5. Goldenberg MR, Rozanski LT, Degeratu FT, Berger BC. Papillary muscle rupture after chordal sparing mitral valve replacement. J Heart Valve Dis. 1998;7:590-2.

\title{
Aortic dissection without Marfan's syndrome in ankylosing spondylitis
}

Hisato Takagi, MD, PhD, Takayoshi Kato, MD, Yukihiro Matsuno, MD, PhD, Yukio Umeda, MD, PhD, Yukiomi Fukumoto, MD, PhD, Yoshio Mori, MD, PhD, and Hajime Hirose, MD, PhD, Gifu, Japan

\footnotetext{
From the First Department of Surgery, Gifu University School of Medicine, Gifu, Japan.

Received for publication Sept 28, 2003; accepted for publication Oct 2, 2003.

Address for reprints: Hisato Takagi, MD, PhD, First Department of Surgery, Gifu University School of Medicine, 40 Tsukasa, Gifu 500-8705, Japan (E-mail: h-takagi@cc.gifu-u.ac.jp).

J Thorac Cardiovasc Surg 2004;127:600-2

$0022-5223 / \$ 30.00$

Copyright $\odot 2004$ by The American Association for Thoracic Surgery doi:10.1016/j.jtcvs.2003.10.018
}

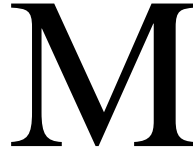

utations in the gene for fibrillin-1 (FBN1), which cause Marfan's syndrome, have been found not only in Marfan's syndrome but also in a range of connective tissue disorders collectively termed "fibrillinopathies," such as isolated ascending aortic aneurysm and dissection, ${ }^{1,2}$ isolated skeletal features, predominant skeletal manifestations without aortic dilatation, isolated ectopia lentis, and other variants. On the other hand, Simkin ${ }^{3}$ has hypothesized that the defective fibrillin of Marfan microfibrils and the inflammationtargeted fibrillin of ankylosing spondylitis may each lead to comparable structural phenotypes of failure. Two cases of coexistent ankylosing spondylitis and Marfan's syndrome without aortic dissection have been reported in the literature. ${ }^{4,5}$ To our knowledge, however, there have been no cases of aortic dissection in ankylosing spondylitis. Here we describe the first case of Stanford type A (DeBakey type I) acute aortic dissection without Marfan's syndrome in human leukocyte antigen (HLA)-B27-negative ankylos- 


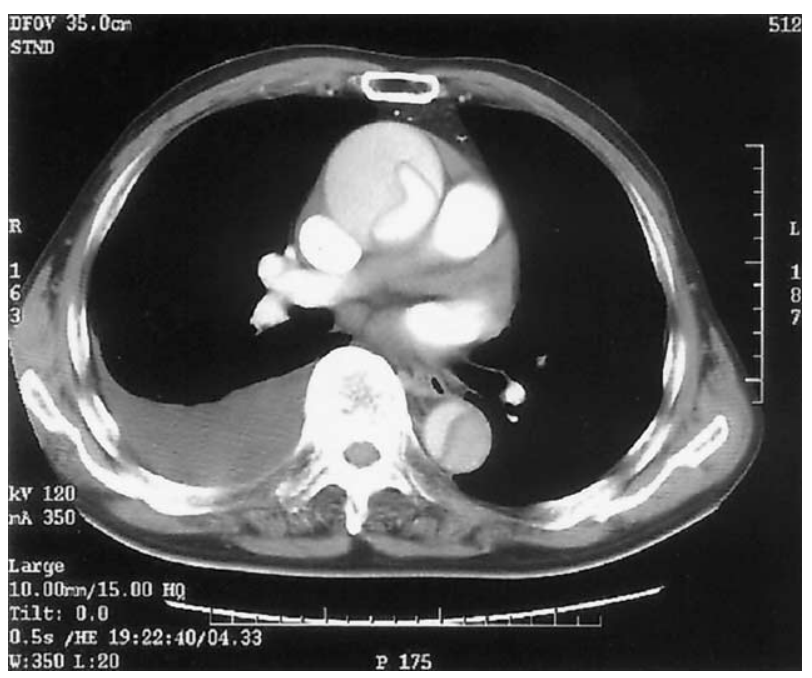

Figure 1. Computed tomography scanning disclosed Stanford type A (DeBakey type I) aortic dissection.

ing spondylitis, and the relationship of these 2 disorders is discussed.

\section{Clinical Summary}

A 65-year-old man with severe chest and back pains was referred to our department. He presented with no traits of Marfan's syndrome in physical examination. Computed tomography scanning disclosed Stanford type A (DeBakey type I) aortic dissection (Figure 1). Urgent replacement of the ascending aorta and the total aortic arch was successfully performed with the use of selective cerebral perfusion. The pathological examination of the aortic wall revealed neither aortitis nor cystic medial necrosis. Postoperatively, abdominal $\mathrm{x}$-ray photography disclosed the characteristic deformation of the lumbar vertebrae, so-called "bamboo spine" (Figure 2). The patient was HLA-B27-negative but met the European Spondylarthropathy Study Group preliminary criteria for the classification of spondylarthropathy proposed by Dougados and associates $^{6}$ : inflammatory spinal pain, alternate buttock pain, and sacroiliitis. His postoperative course was uneventful, and he is doing well now 2 years and 4 months after the operation.

\section{Discussion}

According to Francke and associates, ${ }^{1}$ a G-to-A transition at nucleotide 3379, predicting a Gly1127Ser substitution, has been revealed by single-strand conformation analysis of the entire fibrillin-1 (FBN1) cDNA of 10 kindred individuals in whom ascending aortic disease, ranging from mild aortic root enlargement to aneurysm and/or dissection, has been identified, and none of whom had classical Marfan's syndrome. Pulse-chase studies revealed normal fibrillin synthesis but reduced fibrillin deposition into the extracellular matrix in cultured fibroblasts from a Gly1127Ser carrier. Milewicz and collaborators ${ }^{2}$ have also identified a missense mutation, D1155N in exon 27, in a 44-year-old man who did not have dolichostenomelia, arachnodactyly, myopia, or lens dislocation and who presented with 6- to 7-cm dilatation of his aortic root with an acute dissection of his ascending thoracic aorta. The mutation decreased the amount of fibrillin-1 deposited into the pericellular

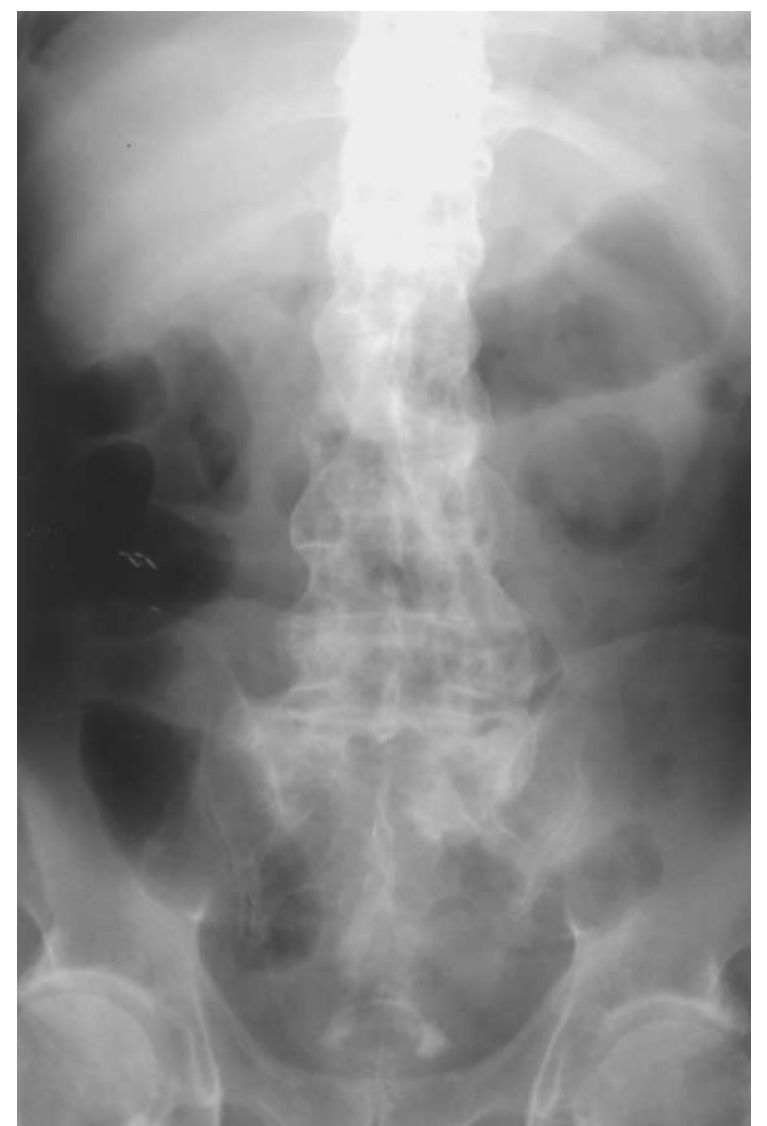

Figure 2. Abdominal x-ray photography disclosed the characteristic deformation of the lumbar vertebrae, so-called "bamboo spine."

matrix of dermal fibroblasts from the affected individual. Results of these studies have supported the hypothesis that FBN1 mutations cause thoracic aortic aneurysm or dissection in patients who do not have Marfan's syndrome. On the other hand, Simkin ${ }^{3}$ reported that most sites of inflammation in patients with ankylosing spondylitis involve fibrocartilage, and that fibrillin-1, a major component of the microfibrils in fibrocartilage, may be the target of this response in the aorta and the eye as well as in bones and joints. Thus, it has been hypothesized that spondylitic inflammation may include release and activation of latent transforming growth factor- $\beta$ from binding sites on fibrillin- 1 .

Fietta and Manganelli ${ }^{4}$ reported a 46-year-old man with coexistent ankylosing spondylitis and Marfan's syndrome without aortic dissection. The patient had the typical traits of Marfan's syndrome, along with the clinical and radiological findings of ankylosing spondylitis in which HLA typing was positive for the B27 antigen. Because of the rarity of such coexistence, at first they thought that it was accidental. The hypothesis suggested by Simkin, ${ }^{3}$ however, led them to reconsider this condition: both a genetically determined and an inflammation-derived fibrillin-1 defect might coexist in their patient. ${ }^{7}$

Although there have been 2 case reports of coexistent ankylosing spondylitis and Marfan's syndrome without aortic dissection in the literature, ${ }^{4,5}$ no cases of aortic dissection in ankylosing spondylitis have been found. In the present case, there is no evidence 
that ankylosing spondylitis and aortic dissection without Marfan's syndrome are not coincidentally but causally related, because neither FBN1 nor fibrillin-1 was examined. The extremely rare coexistence of these 2 disorders, however, may support the hypothesis proposed by Simkin. ${ }^{3}$

\section{References}

1. Francke U, Berg MA, Tynan K, Brenn T, Liu W, Aoyama T, et al. A Gly1127Ser mutation in an EGF-like domain of the fibrillin-1 gene is a risk factor for ascending aortic aneurysm and dissection. Am J Hum Genet. 1995;56:1287-96.
2. Milewicz DM, Michael K, Fisher N, Coselli JS, Markello T, Biddinger A. Fibrillin-1 (FBN1) mutations on patients with thoracic aortic aneurysms. Circulation. 1996;94:2708-11.

3. Simkin PA. Acetabular osteitis in ankylosing spondylitis: dose fibrillin figure in its pathogenesis? J Rheumatol. 2001;28:2663-6.

4. Fietta P, Manganelli P. Coexistent Marfan's syndrome and ankylosing spondylitis: a case report. Clin Rheumatol. 2001;20:140-2.

5. Rovensky J, Zlnay M, Zlnay D. Marfans syndrome and ankylosing spondylitis. Isr Med Assoc J. 2003;5:153.

6. Dougados M, van der Linden S, Juhlin R, Huitfeldt B, Amor B, Calin A, et al. The European Spondylarthropathy Study Group preliminary criteria for the classification of spondylarthropathy. Arthritis Rheum. 1991;34:1218-27.

7. Fietta $P$, Manganelli P. Is fibrillin-1 the link between ankylosing spondylitis and Marfan's syndrome? J Rheumatol. 2002;29:1808.

\section{Total magnetic vascular coupling for arterial revascularization}

Uwe Klima, MD, PhD, Michael Maringka, MD, Eric Bagaev, MD, S. Kirschner, CM, and Axel Haverich, MD, PhD, Hannover, Germany

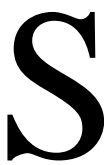
everal new automatic proximal and distal anastomotic devices are in practical use. Their clinical performance, feasibility, and angiographic follow-up have been described. ${ }^{1,2}$ Most authors report on a single automatic anastomosis using a saphenous vein graft. Total arterial revascularization using beating heart techniques is suggested by many authors to be the method of choice for revascularization. ${ }^{3}$ However, to our knowledge, such an operation by means of automatic anastomotic devices has not been reported.

We describe the clinical and angiographic follow-up of a patient who underwent total arterial revascularization on the beating heart in which all anastomoses were performed with an automatic anastomotic magnetic coupling system, the Ventrica Magnetic Vascular Positioner (MVP) Distal Anastomosis System (Ventrica, Inc, Fremont, Calif).

\section{Clinical Summary}

A 69-year-old man with a 12-month history of angina (preoperative New York Heart Association III) underwent cardiac catheterization revealing 3 vessel disease with significant stenosis $(>70 \%)$ of all 3 main coronary arteries. Total arterial revascularization was performed

\footnotetext{
From the Division of Thoracic and Cardiovascular Surgery, Medical School, Hannover, Germany.

Received for publication Aug 11, 2003; revisions requested Sept 2, 2003; accepted for publication Sept 10, 2003.

Address for reprints: Uwe Klima, MD, PhD, Department of Thoracic and Cardiovascular Surgery, Hannover Medical School, 30623 Hannover, Germany (E-mail: klima@thg-mh.hannover.de).

J Thorac Cardiovasc Surg 2004;127:602-3

$0022-5223 / \$ 30.00$

Copyright $\odot 2004$ by The American Association for Thoracic Surgery doi:10.1016/j.jtcvs.2003.09.050
}

using the right and left internal thoracic arteries (ITAs) and the left radial artery (RA). The surgical approach was through a median sternotomy. All target arteries were exposed using the Octopus 4 Tissue Stabilizer and Starfish Heart Positioner (Medtronic, Inc, Minneapolis, Minn). The patient was given an antiplatelet regi-

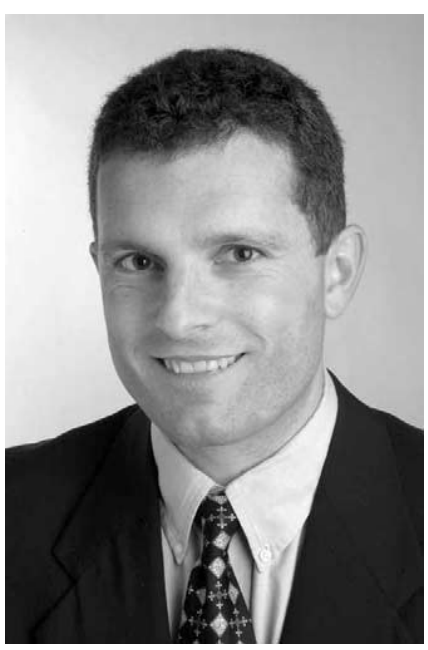

Dr Klima men of $150 \mathrm{mg}$ of clopi-

dogrel (Plavix; Bristol-Myers Squibb, New York, NY) and 100 $\mathrm{mg}$ of aspirin the day before surgery and received $300 \mathrm{IE} / \mathrm{kg}$ of heparin to maintain an activated coagulation time level of more than 350 seconds during the procedure.

All 4 anastomoses were performed with the Ventrica MVP Distal Anastomosis System. The system consists of 6 magnetic clips, with 3 clips forming a set. One magnetic clip set is positioned into the target artery, and the other is positioned into the bypass graft using a preloaded delivery system. These ports then form an anastomosis by magnetic coupling (Figure 1). The first anastomosis created was the left ITA to LAD. The RA was then coupled distally to the circumflex artery, and after shortening the RA, a T-graft anastomosis was also performed to the left ITA with the magnetic coupler. The right coronary artery required an endarterectomy before the fourth automatic anastomosis with the right ITA was performed. The 4 connections were each created in less than 90 seconds.

The patient's intraoperative and postoperative courses were uneventful. A control cardiac catheterization on postoperative day 6 showed all grafts and anastomosis patent (Figure 2). The patient was discharged on postoperative day 10. Ten weeks after surgery the patient is clinically doing well. He is pain free and was able to reach $125 \mathrm{~W}$ for 2 minutes while undergoing an exercise stress test. 